\title{
Skill transfer through multi-sport play: A tennis and hockey example
}

\author{
E. Paul Roetert ${ }^{\mathrm{a}}$, Ola Malmqvist ${ }^{\mathrm{a}}$, Karl Davies ${ }^{\mathrm{a}}$ \& Richard Way ${ }^{\mathrm{b}}$
}

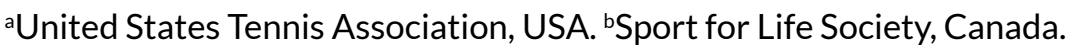

\begin{abstract}
The concept of "skill transfer" is introduced with the sports of ice hockey and tennis as examples. Skill transfer is addressed with a backdrop and understanding that it is based on existing concepts that have been researched significantly over the past few decades. They include Physical Literacy, Early Sport Specialization and Long-Term Athlete Development. Specific commonalities and skill benefits are highlighted. This purpose of this inclusive approach is to provide coaches with a catalyst to better understanding of the benefits of skill transfer in light of learning physical activities through two sport examples on multiple surfaces.
\end{abstract}

Key words: skill transfer, multisport play, commonalities.

Received: 9 August 2021

Accepted: 20 September 2021

Corresponding author: E. Paul Roetert.Email: paul.roetert@usta. com

\section{INTRODUCTION}

Over the past few decades much has been written about the construct of Physical Literacy (Aspen Institute, 2015; Durden-Myers and Whitehead, 2018; IPLA, 2014; Roetert et al 2017). Understanding this construct is important because people who are physically literate have the competence, confidence and motivation to enjoy a variety of sports and physical activities. As a result, they are more likely to stay active throughout their lifetime (Roetert, et al. 2017). The definition of Physical Literacy, as determined by the International Physical Literacy Association is as follows: "Physical literacy is the motivation, confidence, physical competence, knowledge, and understanding to value and take responsibility for engagement in physical activities for life" (IPLA, 2014). In other words, physical literacy should be considered a journey, not a destination, which means you can spend your whole life developing it. This is an important principle to keep in mind for both coaches and sport scientists. Fortunately, several different countries, sectors of society and sports organizations have started endorsing this concept (Aspen Institute, 2015).

In addition, the topic of Early Sport Specialization has also received deserved attention (Jayanthi et al, 2013; LaPrade et al 2016). Although youth sport participation offers many benefits, an overemphasis on competitive success, often driven by an additional misguided over-emphasis on goals of elite-level travel team selection, collegiate scholarships, Olympic and National team membership and even professional contracts, has seemingly become widespread. This has resulted in an increased pressure to begin highintensity training at young ages. Such an excessive focus on early intensive training as well as competition results at young ages, rather than skill development, can lead to overuse injury and burnout (DiFiori et al 2014). As it relates to junior tennis tournament scheduling as well as maximizing future performance and minimizing injuries, late specialization and intensive training may be the most optimum path towards

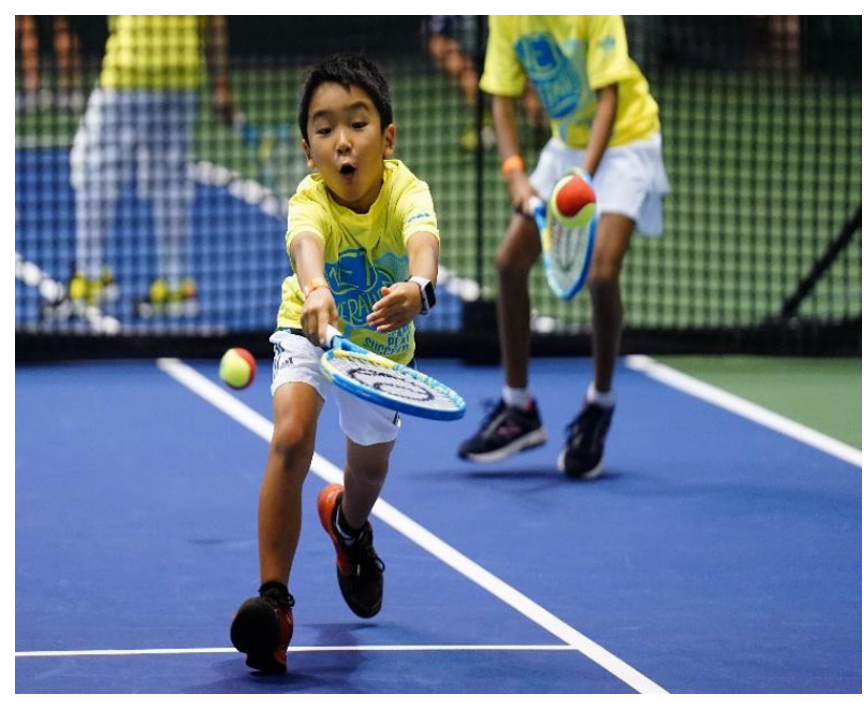

Figure 1. Learning Balance and Coordination Skills.

healthy elite level success. This does not necessarily mean that the volume of training should be increased. Specific weekly amounts of training, annual amounts of competition, and match volumes within tournaments, as well as physical and biomechanical evaluations should be included in making decisions regarding junior competitive tennis players' development. This responsibility belongs to coaches, as they are often the most influential group that determines the amount of necessary training and competition (Jayanthi et al, 2013).

A third topic that has also come to the forefront in the last few decades is Long Term Athlete Development - LTAD (Balyi et al, 2018) and its U.S. focused derivative, the American Development Model (ADM, 2021). LTAD is based on the premise that kids and adults will become active, stay active, and some even reach the greatest heights of sport achievement if they do the right things at the right times. 
In other words, what can be accomplished at each stage of human development to give every child the best chance of engaging in lifelong, health-enhancing physical activity? For those athletes with drive and talent, there is a sevenstage framework which guides the participation, training, competition and recovery pathways in sport and physical activity (Balyi et al, 2018; Higgs et al, 2019). Recent research shared by Till et al (2021) provides coaches with a framework on what can be planned and delivered within a coaching session, across multiple ages and stages of development and in multiple contexts. In the early LTAD work, sports were categorized into two groups: early and late specialization. This created a lively debate in tennis regarding the timing of specialization. As work was done across more than 60 sports, Higgs et al (2019) identified further categorization occurred to guide the creation of athlete development frameworks. Specifically, a group of sports including tennis and ice hockey were categorized as 'early initiation-late specialization' highlighting their high level of technical and tactical skill combined with long-term development of physical capability.

These three above-named concepts are inter-related and a thorough understanding of each can play a vital role in an athlete's success at all levels of development. With that in mind, we hereby introduce an area that thus far has received less attention in the literature which is the idea of sport related "skill transfer". Skill transfer, similar to the more often referenced and related topic of talent transfer, currently lacks an evidence-based direction and approach in the scientific literature. We believe that further research into the understanding of skill transfer is needed in order to develop an evidence base for this concept. It is important to understand that the three topics of LTAD, Early Sport Specialization and Physical Literacy form an important backdrop to the concept of Skill Transfer from one sport to another (Collin et al, 2014; MacNamara \& Collins, 2015). In that context, this article provides a brief example of skill transfer between two seemingly unrelated sports, tennis and ice hockey. The article is written from the perspective that the sport of hockey may provide an excellent preparation for tennis success for a variety of reasons hereby outlined. Although the athletes highlighted achieved their great accomplishment status a number of decades ago, the concepts outlined in this article still hold and many young athletes continue to benefit from the cross-over experience.

\section{AN ELITE SPORT EXAMPLE OF SKILL TRANSFER FROM HOCKEY TO TENNIS}

Although tennis and ice hockey appear as very disparate sports, quite a few players' names can be brought up as it relates to playing both ice hockey and tennis in their formative years. As an example, many of the male Swedish tennis players are known for growing up playing both sports. Joakim Nystrom, who grew up in Skelleftea, a town in the Northeastern part of Sweden was an accomplished junior hockey player, yet gave up playing the sport at a higher level once tennis became a better way to pay the bills and see the world. Bjorn Borg, who grew up just outside of Stockholm and a winner of 11 Grand Slam singles titles, also was an outstanding junior ice hockey player. Although growing up in different parts of the country, both played ice hockey from a very young age, similar to a number of other Swedish tennis players who became successful professionals.

Even more amazing is the skill transfer at the highest levels of competition in hockey and tennis, featuring Jaroslav
Drobný and Ion Tiriac. Drobny was a star center in the Czechoslovakian ice hockey league, leading the Czech National Ice Hockey Team to a Gold Medal at the 1947 World Championships and a Silver Medal in the 1948 Olympic Games played at St. Moritz, Switzerland. Drobny showcased his talents by scoring nine goals in eight games during the Olympics (ITHOF, 2021). In addition to his hockey skills, as a singles tennis player, he won the French Championships (now called the French Open Championships) in 1951 and 1952 as well as Wimbledon in 1954. Overall, he reached 13 major finals in Grand Slam events including singles, doubles, and mixed doubles. Tiriac, was an excellent ice hockey defenseman representing his native Romania at the 1964 Winter Olympics which were held in Innsbruck, Austria. Shortly after that, he switched to tennis, reaching the Davis Cup finals several times in the late 1960s and early 1970s. He also captured a Grand Slam tournament title by winning the doubles event at the French Open in 1970 with his partner Ilie Nastase.

\section{COMMONALITIES}

Physical: Both hockey and tennis involve the concepts of balance and control while tracking the puck or ball and moving towards an anticipated target in space where the puck/ball is predicted to be. This type of movement involves additional physical skills such as agility, strength, timing and coordination. Being aware of all these factors is all the more complicated because one or more opponents and teammates (i.e. doubles in tennis) are also moving. Therefore, spatial awareness becomes a key component of moving in space (Roetert et al, 2017). Stopping, starting and receiving skills are shared elements that cannot be overlooked by players in both sports. Finally, although tennis is often played on hardcourt surfaces, clay court- and grass court surfaces can also be found and allow for sliding movements not dissimilar to skating on ice especially when the skate is sliding sideways to stop or to allow for a change of direction. In fact, many similar muscle groups are employed in all of the abovenamed skills. These are reasons that make hockey as a team sport, and tennis as an individual sport good partner sports.

Affective: Based on learning how to develop the necessary skills to explore speed, balance, decision-making and body control with opponents and partners, players will build the belief in their ability to perform a particular activity or skill. This is called self-efficacy. When players develop self confidence in one sport and approach an activity that has similar skill requirements, it heightens their self-efficacy which increases the motivation to excel. The very nature of being off-balance, hitting the ball from different areas of the court and often changing directions puts players in a position where they learn about managing control over their balance and thereby self-confidence. Skating and shot-selection skills can help provide this sense of balance as well as decisionmaking process. Having developed a competent degree of physical literacy, properly mastering movement patterns and confidence on ice, tennis becomes a sport that can be equally meaningful and motivating. As importantly, the early exposure of a team sport, such as hockey, can provide a great platform from a social perspective, prior to, or throughout the learning stages of tennis development (Balyi et al, 2018).

Cognitive: Social emotional skills that influence one's behavior in tennis, an individual sport and hockey, a team sport, can vary greatly. Thus, athletes are better able to gain broader perspectives and hone their skills at managing 
emotion, showing empathy, and setting and achieving goals. As Stanec (2021) advised "encouraging youth to participate in two sports with different cultures and traditions, can help them broaden their worldview which leads to many social and emotional benefits, including relationship skills and social awareness". For example, dealing with adversity and problem-solving can lead to a stronger ability to cope with the inherent stresses of both sports. This in turn can foster greater self-reliance which can allow players to become better leaders and mentors in a variety of sports settings.

\section{Table 1}

Key Commonalities and Transferable Skills between Tennis and Ice Hockey.

\begin{tabular}{|c|c|}
\hline $\begin{array}{l}\text { Analytical } \\
\text { Reasoning: }\end{array}$ & $\begin{array}{l}\text { The ability to take in information to recognize } \\
\text { patterns of play, in both sports. This is done in } \\
\text { dynamic environments often switching rapidly } \\
\text { between offensive and defensive situations. } \\
\text { These cognitive developments serve athletes } \\
\text { well in both sports. }\end{array}$ \\
\hline Anticipation: & $\begin{array}{l}\text { Learning where the puck/ball is going to be based } \\
\text { on the position, skills and typical patterns of play } \\
\text { of the opponent. }\end{array}$ \\
\hline Balance: & $\begin{array}{l}\text { Emphasizing balance and control of movements } \\
\text { while sliding (clay and grass court tennis) or } \\
\text { running at different speeds when athletes are } \\
\text { first introduced to these environments is key. }\end{array}$ \\
\hline $\begin{array}{l}\text { Decision } \\
\text { Making: }\end{array}$ & $\begin{array}{l}\text { Hockey is a game of high speed decision making } \\
\text { based on anticipating patterns and speed of } \\
\text { movement to propel a puck to a specific place } \\
\text { where the teammate can get to it. Tennis } \\
\text { requires high speed decision making to propel } \\
\text { the ball where the opponent cannot get to it. } \\
\text { Same skill-different purpose! }\end{array}$ \\
\hline Footwork: & $\begin{array}{l}\text { Controlling footwork, edging of the skate, cross- } \\
\text { over of feet and rapidly changing direction, } \\
\text { are critically important in hockey and directly } \\
\text { transferable to developing tennis players. }\end{array}$ \\
\hline $\begin{array}{l}\text { Foundational } \\
\text { Movement } \\
\text { Skills: }\end{array}$ & $\begin{array}{l}\text { Applying foundational movement skills in new } \\
\text { situations will help in addressing decision- } \\
\text { making in game/match situations. }\end{array}$ \\
\hline $\begin{array}{l}\text { Psycho- } \\
\text { behavioral: }\end{array}$ & $\begin{array}{l}\text { These learned skills and behaviors } \\
\text { include: Commitment and determination, } \\
\text { Self-confidence, Coping skills, Focus and } \\
\text { discipline, Goal setting, Motivation, Realistic } \\
\text { performance evaluation. }\end{array}$ \\
\hline $\begin{array}{l}\text { Speed and } \\
\text { Agility: }\end{array}$ & $\begin{array}{l}\text { Stopping, starting and changing direction all } \\
\text { happen on a regular basis in both sports. These } \\
\text { multi-directional skills form the basis for learning } \\
\text { how to control your center of gravity in balanced } \\
\text { as well as unbalanced positions. }\end{array}$ \\
\hline
\end{tabular}

\section{RECOMMENDATIONS FOR TENNIS COACHES}

- Tennis facilities may want to look towards hockey programs to find athletes that have developed the physical and cognitive skills which can form the foundation for tennis technical skills to be built upon.

- Tennis programs can make a connection with ice hockey programs to work together for off-ice training to advance hockey skill development.

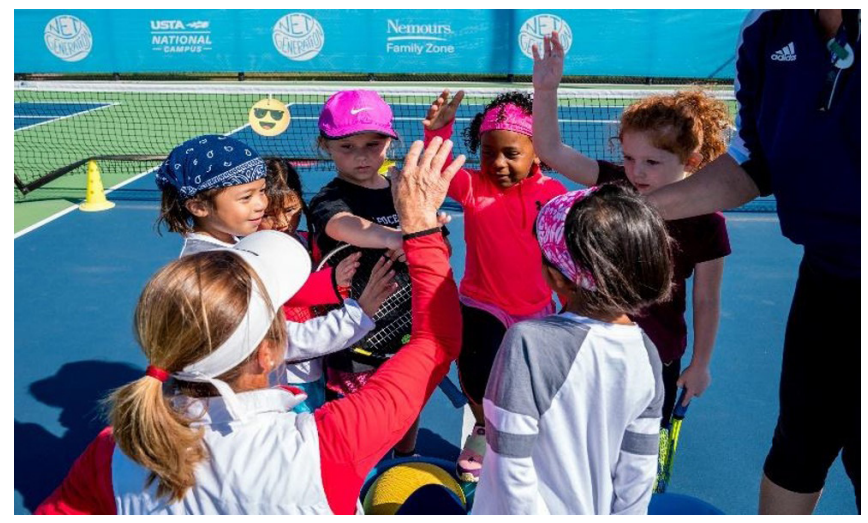

Figure 2. Building Relationship Skills.

- Although this article focused specifically on the relationship between ice hockey and tennis, other forms of hockey could (and should) also be considered. These include, field hockey, street hockey and roller hockey.

- Children participating in both sports benefit from a wider range of fun and diversity in their development as athletes. Instead of extra training in one sport which risks burn-out and chronic injury, tennis and hockey can be developed through the other sport thus finding the sweet spot of fun and sport development (Aspen Institute, 2015; Jayanthi et al 2015; Jayanthi et al, 2018).

\section{CONCLUSIONS}

Although played on different surfaces, the sports of ice hockey and tennis have a lot more in common than many people would expect. Certainly, the case can be made that other individual and team sports share commonalities and transferable skills that might set players up for success, however tennis and hockey are both tremendously dynamic sports combining repeated multi-hour physical exertion and the skill of hitting a ball/puck with controlled force using an implement. In addition, opponents are battling fatigue to outwit each other in a game of strategy. These elements should be considered as benefits. Foundationally, there is a need for tennis players to develop and continuously improve their physical literacy in developing the competence, confidence, desire and motivation to enjoy sport.

The four highlighted players in this article all started early with hockey as their early team sport and ended up focusing on tennis as their individual sport (ITHOF, 2021). We recommend future research to investigate if this is a best practice model. Very important is the time of specialization to ensure early intensity does rob athletes of long-term success. Therefore, in the development framework 'early initiation-late specialization' encourages athletes to develop skill through multiple sport activities prior to specializing in one sport. Thus it is important to understand the connection between ice hockey and tennis where the list of commonly shared concepts and skills transfer very well from one sport to another.

\section{CONFLICT OF INTEREST AND FUNDING}

The authors declare that they do not have any conflict of interest and that they did not receive any funding to conduct the research. 


\section{REFERENCES}

Balyi, I., Way, R. \& Higgs C. (2018). Long-Term Athlete Development. Champaign, IL: Human Kinetics.

Collin, R., Collins, D., Jones M., \& MacNamara Á. (2014). Change of plans: An evaluation of the effectiveness and underlying mechanisms of successful talent transfer. Journal of Sports Sciences. 32, 16211630. doi: 10.1080/ 02640414.2014;908324 PMID: 248144749. https://doi.org/10.1080/02640414.2014.908324

DiFiori, J., Benjamin, H., Brenner, J., Gregory, A., Jayanthi, N., Landry G., \& Luke A. (2014). Overuse injuries and burnout in youth sports: a position statement from the American Medical Society for Sports Medicine. British Journal of Sports Medicine. 48, 287-288. https://doi.org/10.1136/bjsports-2013-093299

Durden-Myers, E. \& Whitehead, M. (2018). Operationalizing physical literacy: Special issue editorial. Journal of Teaching in Physical Education. 37, 234236.https://doi.org/10.1123/jtpe.2018-0130

Farrey, T. \& Isard, R. (2015). Physical literacy in the United States: A model, strategic plan, and call to action. Washington, DC: The Aspen Institute.

Higgs C, Way R, Harber V, Jurbala P, Balyi I (2019). Long-term development in sport and physical activity 3.0. Sport for Life.

International Physical Literacy Association (2014). Retrieved August 4, 2014 from https://www.physical-literacy.org.uk

International Tennis Hall of Fame. - ITHOF (2021). Retrieved July 19, 2021 from https://www.tennisfame.com
Jayanthi, N., Pinkham, C., Dugas, L., Patrick, B. \& Labella C. (2013). Sports specialization in young athletes: evidence-based recommendations. Sports Health. 5, 251-257.https://doi.org/10.1177/1941738112464626

LaPrade, R. F., Agel, J., Baker, J., Brenner, J. S., Cordasco, F. A., Côté, J., ... \& Provencher, M. T. (2016). AOSSM early sport specialization consensus statement. Orthopaedic Journal of Sports Medicine, 4(4), 2325967116644241. https://doi.org/10.1177/2325967116644241

MacNamara, Á. \& Collins, D. (2015). Second chances: investigating athletes' experiences of talent transfer. PloS one, 10(11), e0143592.https://doi. org/10.1371/journal.pone.0143592

Roetert, E.P., Ellenbecker, T., \& Kriellaars, D. (2018). Physical literacy: Why should we embrace this construct? British Journal of Sports Medicine. 52, 1291-1292.

Stanec A. (2021). Sport and Activity Research. Retrieved 19th July 2021 from https://www.movelivelearn.com/offerings/\#Sport-and-Physical-ActivityResearch

Till, K., Eisenmann, J., Emmonds, S., Jones, B., Mitchell, T., Cowburn, I., Tee, J., Holmes, N., \& Lloyd R. (2021). Coaching Session Framework to Facilitate Long-Term Athletic Development. Strength and Conditioning Journal. 43(3), 43-55. https://doi.org/10.1519/SSC.0000000000000558

United States Tennis Association (2021). American Development Model, downloaded from: https://www.usta.com/en/home/play/americandevelopment-model.html.

Copyright (c) 2021 E. Paul Roetert, Ola Malmqvist, Karl Davies \& Richard Way

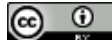

This text is under a Creative Commons BY 4.0 license

You are free to Share - copy and redistribute the material in any medium or format - and Adapt the content - remix, transform, and build upon the material for any purpose, even commercially under the following terms:

Attribution: You must give appropriate credit, provide a link to the license, and indicate if changes were made. You may do so in any reasonable manner, but not in any way that suggests the licensor endorses you or your use. 